\title{
Palliative Modified Radical Mastectomy to Improve Quality of Life by Decreasing Disease Burden: A Case Report
}

Sohayla Rostami ${ }^{1^{*}}$, Seth B. Ladd ${ }^{1}$, Linda Stewart ${ }^{1}$, Jackie Battista ${ }^{1}$

${ }^{1}$ Department of Surgery, St. Johns Episcopal Hospital, Far Rockaway, New York, USA

Corresponding Author: Sohayla Rostami, DO ${ }^{\text {ORCID iD }}$

Address: Department of Surgery, St John’s Episcopal Hospital, 327 Beach 19th St, Queens, NY 11691, United States. Email:srostami@ehs.org

Received date: 02 June 2021; Accepted date: 26 June 2021; Published date: 02 July 2021

Citation: Rostami S, Ladd SB, Stewart L, Battista J. Palliative Modified Radical Mastectomy to Improve Quality of Life by Decreasing Disease Burden: A Case Report . Asp Biomed Clin Case Rep. 2021 Jul 02;4(2):119-24.

Copyright (C) 2021 Rostami S, Ladd SB, Stewart L, Battista J. This is an open-access article distributed under the Creative Commons Attribution License, which permits unrestricted use, distribution, and reproduction in any medium provided the original work is properly cited.

\begin{abstract}
In cases of advanced pathology, palliative medicine is able to confer a great deal of relief to the patient. In the same light, surgical intervention is able to provide increased quality of life in cases of extensive disease burden, providing palliation where curative measures cannot be achieved. In the case study therein, a patient presents with metastatic breast cancer with a localized fungating mass contributing to severe local and systemic symptomatology. In this setting, invasive management of her disease allowed for clinical improvement of the patient when medical management alone was not sufficient. The patient quickly demonstrated recovery of her symptoms in the post-operative phase when the local disease was resected. The utilization of invasive measures, as seen in this case, further proves the importance of multidisciplinary palliative care where surgical measures are included in patient care.
\end{abstract}

\section{Keywords}

Palliative Surgery, Palliative Medicine, Mastectomy, Disease Burden, Quality of Life

\section{Introduction}

With modern advancements, medicine is better able to detect terminal ailments and means of prolonging life. In the context where curative care cannot be provided, palliative care addresses areas of patient life which may be improved, granting quality and comfort during dire situations. With the use of palliative medicine, the involvement of some specialties has not been clearly defined. This case explores the role of surgery in palliative care and allowing surgeons to be considered part of the palliative team.

The patient, in this case, was diagnosed with infiltrating poorly differentiated ductal carcinoma seven months prior to operative intervention. She presented with a fungating left breast mass and secondary symptoms. The patient was admitted for treatment of her sepsis prior to having a palliative left modified radical mastectomy. Following the operation, the patient clinically improved with concomitant normalization of her overall symptomatology, previously unsuccessful with medical management.

As demonstrated, palliative surgery proved to be a safe and reasonable option that was used successfully for therapeutic means. The intervention decreased the burden of disease in the patient near the end of life, conferring comfort when other options could not. The 
Citation: Rostami S, Ladd SB, Stewart L, Battista J. Palliative Modified Radical Mastectomy to Improve Quality of Life by Decreasing Disease Burden: A Case Report . Asp Biomed Clin Case Rep. 2021 Jul o2;4(2):119-24.

\section{Case Report}

case therein demonstrates the importance of including surgeons within the palliative conversation and goals of care.

\section{Case Description}

A 62-year-old female presented to the hospital for symptomatic anemia, weakness, and pain localized to a large fungating mass of the left breast. The patient reported increasing pain and drainage from the mass, interfering with her daily activities. The patient was diagnosed with infiltrating poorly differentiated ductal carcinoma in situ seven months' prior at a different facility. Upon diagnosis, the patient underwent surgery and chemotherapy. However, due to dissatisfaction with the outcome, she stopped her treatment prematurely.

Physical exam revealed a pedunculated mass with indurations and serosanguinous discharge. The mass encompassed the left lateral aspect of her breast with intimate involvement of the axillary region. Labs were significant for leukocytosis with a white blood count (WBC) of 29,000 cells $/ \mathrm{mm}^{3}$ and anemia with a hemoglobin of $7.6 \mathrm{~g} / \mathrm{dL}$. Computed Tomography (CT) imaging was significant for a $15.5 \mathrm{~cm} \times 10 \mathrm{~cm} \times 12.5 \mathrm{~cm}$ left breast mass with infiltrating changes throughout. Extensive pulmonary metastatic disease and lytic lesions of the right ribs were reported (Fig-1).

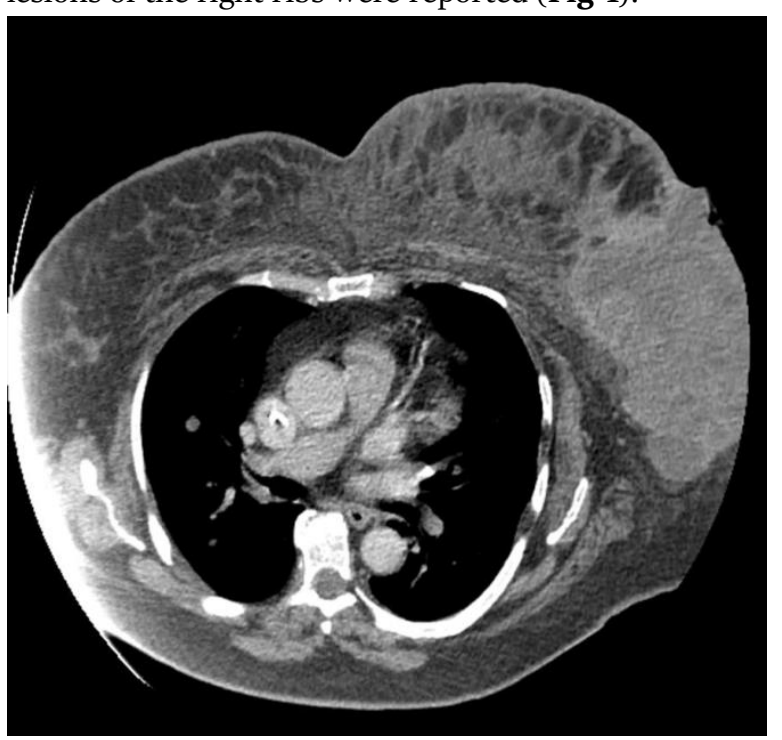

Fig-1: CT Chest

Left breast mass with infiltration of the adjacent breast and skin thickening consistent with primary malignancy, pulmonary metastatic disease and lesions in the ribs noted.
The hospital course revealed worsening systemic symptoms with minimal response to medical management, persistent leukocytosis, febrile episodes, and anemia refractory to blood transfusions. Patient was transfused five units of packed red blood cells (PRBCs) through the early days of her hospitalization. By hospital day nine, the patient exhibited signs of sepsis with WBC increasing to 42 ,0oo cells $/ \mathrm{mm}^{3}$ and febrile episodes. The decision to pursue palliative resection was made, determining that the source of symptoms was the left breast mass.

On hospital day 13, the patient underwent palliative left modified radical mastectomy and wound vacuum placement. Intraoperatively, the patient was found to have an $18 \mathrm{~cm} \times 11 \mathrm{~cm} \mathrm{x} 7 \mathrm{~cm}$ necrotic and hemorrhagic mass in the outer quadrants of the breast (Fig-2). The mass was excised down to the pectoralis muscle, flaps were formed superiorly to the clavicle, medial to the sternal border, and inferiorly to the rectus. Negative wound pressure therapy was initiated with plan for definitive closure when the wound bed was prepared and granulation tissue formed. Pathology confirmed prior diagnosis of infiltrating poorly differentiated ductal carcinoma, high grade with comedo necrosis, and triple negative for Her2/ Neu, estrogen receptor (ER), and progesterone receptor (PR) markers.

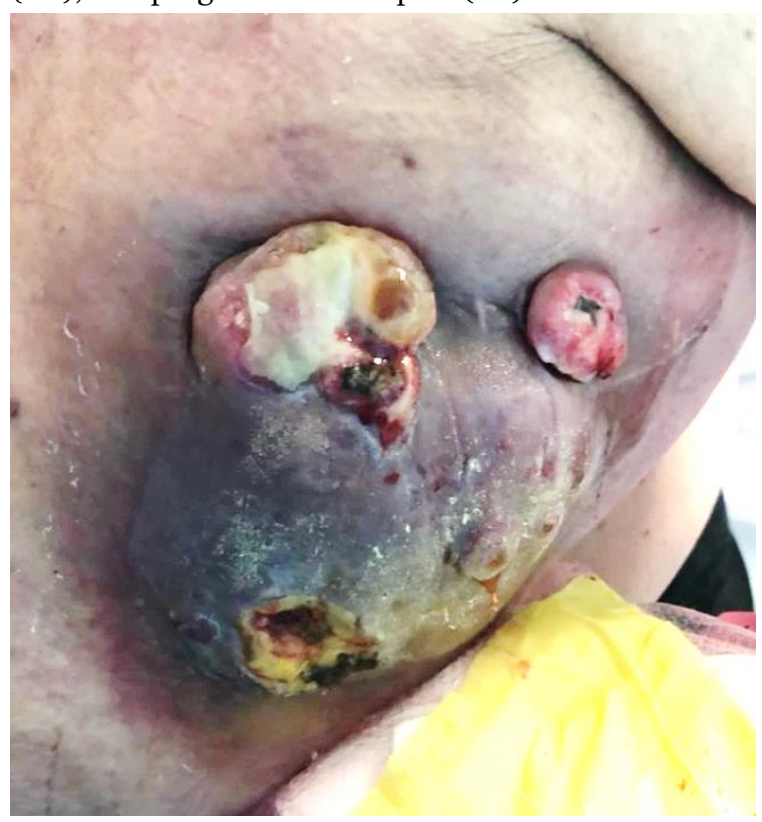

Fig-2: Fungating breast mass on the left breast

Pre-operative fungating breast mass measuring $18 \mathrm{~cm} \times 11$ $\mathrm{cm}$ on the left lateral breast 
Citation: Rostami S, Ladd SB, Stewart L, Battista J. Palliative Modified Radical Mastectomy to Improve Quality of Life by Decreasing Disease Burden: A Case Report . Asp Biomed Clin Case Rep. 2021 Jul 02;4(2):119-24.

\section{Case Report}

In the immediate post-operative days, the WBC trended down and decreased to 16,000 cells $/ \mathrm{mm}^{3}$ with stable hemoglobin. The patient required no further transfusions and remained afebrile with normalization of the WBC for the remainder of the hospitalization. The patient underwent a subsequent surgery 14 days after the initial mastectomy for wound bed preparation and split thickness graft placement, utilizing the left thigh as the donor site (Fig-3 and Fig-4). The graft was successful for wound closure at post-operative day six.

The patient was discharged home by post-operative day 22 from the mastectomy and post-operative day eight from graft placement with outpatient follow up. Subsequent clinic and wound care visit revealed marked improvement in the wound, with good range of motion and without pain or discharge. Patient reported return to her daily activities and improvement in quality of life.

\section{Literature Review}

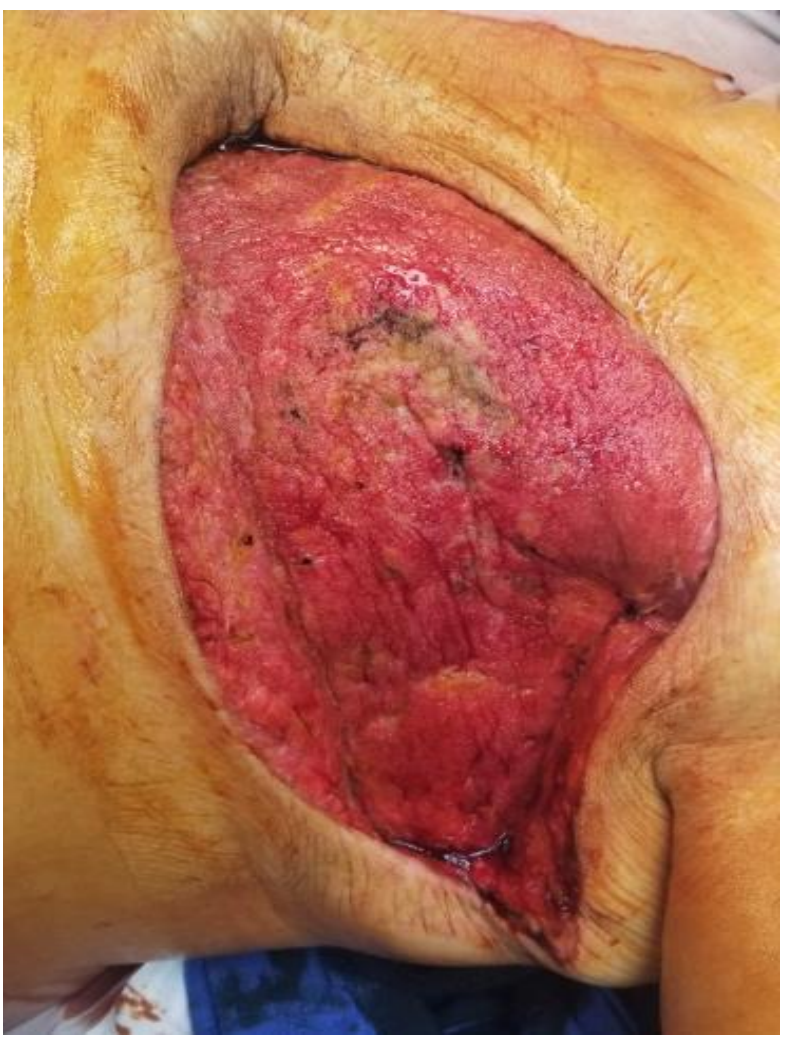

Fig-3: Left chest wall

Status post left modified radical mastectomy, chest wall debridement, 12 days of wound vac placement for granulation tissue formation
The role of surgery in the palliative realm remains unclear. With patients suffering from metastatic and end stage breast cancer, debate remains regarding the long-term survival outcomes after palliative mastectomy. In the last decade, 27 publications entailing case studies and research have attempted to guide the protocols for operative intervention with removal of primary breast tumors in advanced disease. Most of the literature confers the improvement in the quality of life when palliative mastectomy is described. Irrespective of survivability in the face of terminal ailment, 10 studies specifically noted improved outcomes when measured from the palliative perspective [1-10]. A clear delineation is described with improved quality of life measures despite the terminality of the primary cancer. Concurrently, 14 studies noted statistically significant survival rates in individuals who underwent palliative mastectomy [1124]. Of these aggregates, three studies noted no difference in patient survival outcome and concluded with conflicting data [25-27].

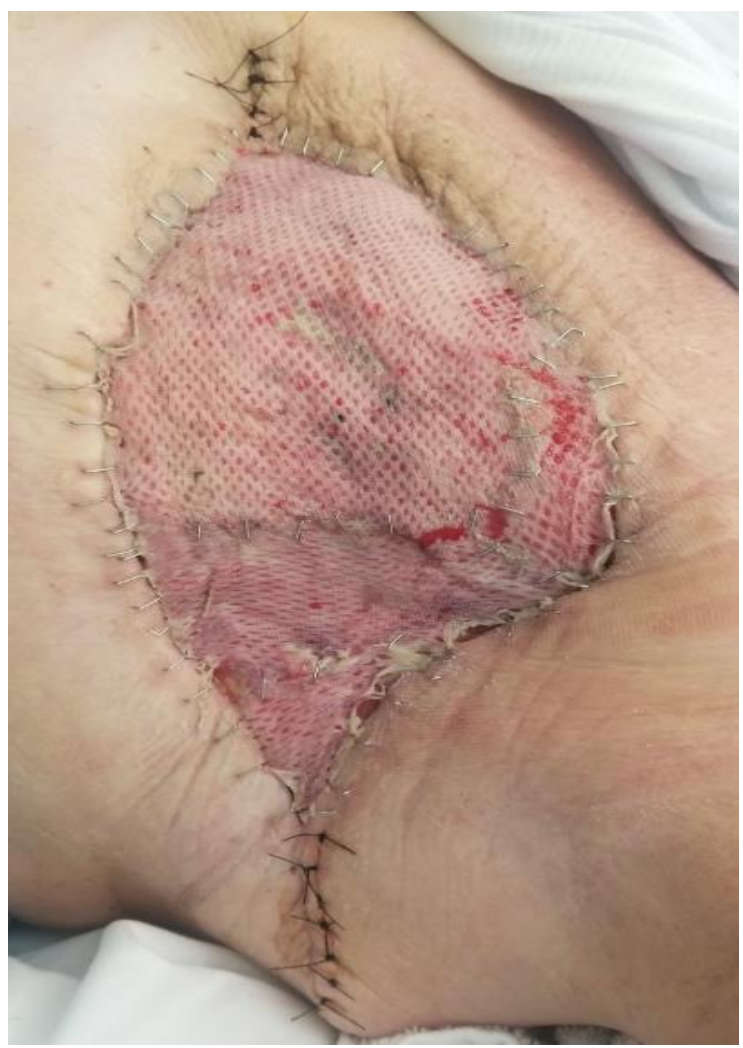

Fig-4: Left chest wall

Status post left chest debridement and split thickness graft placement utilizing left thigh donor site and closure of medial and lateral skin edges 
Citation: Rostami S, Ladd SB, Stewart L, Battista J. Palliative Modified Radical Mastectomy to Improve Quality of Life by Decreasing Disease Burden: A Case Report . Asp Biomed Clin Case Rep. 2021 Jul 02;4(2):119-24.

Case Report

Despite the question of survival, a general consensus is present regarding the benefits of surgical intervention in the stage IV patient cohort when guided by palliation. These documented benefits, although described in a limited manner, provide a guide for surgeons to intervene such that the patients may ultimately benefit. The positive outcomes are noted while also accounting for perioperative morbidity and mortality. The literature supports surgical measures as a variable in palliative care.

\section{Discussion}

Advanced cancer accounts for various complications from both focal and general pathology. This patient presented with Stage IV metastatic breast cancer accompanied by a myriad of symptoms locally and systematically secondary to the growing disease burden. Over the course of months, medical management of the cancer did not adequately address the illness. The patient faced the daily problems of a large local wound from the malignant breast mass and systemic signs and symptoms of the disease, manifesting as severe anemia, leukocytosis, and sepsis.

Surgical intervention with the initial mastectomy allowed for removal of the fungating wound as the source of infection causing systemic symptoms. The subsequent operation aimed to address the closure of the wound as grafting allowed for the increase speed of epithelialization. The positive outcomes of the operation served to be multimodal as the patient exhibited rapid clinical improvement. Likewise, she described enhancement in her quality of life both psychologically and practically as she no longer had to watch the growing mass nor take care of it daily with dressing changes, respectively. Additionally, patient's anemia and leukocytosis resolved, no longer requiring blood transfusions or strong antibiotic use, mitigating additional adverse effects from the required medical interventions. Most importantly, the surgical treatments allowed for the patient's discharge, return to her daily routine, and medical treatments as an outpatient without symptoms of her disease.

\section{Conclusion}

Palliative surgery includes invasive intervention for relief of symptoms in incurable disease processes with the goal of improving quality of life and in some cases, the secondary benefit of increased survival. Palliative surgery remains a new realm in medicine which requires further investigation. In the aforementioned case, a patient suffering from her metastatic disease with grave symptoms presented to the hospital. She qualified as a surgical candidate for left modified radical mastectomy with subsequent split thickness graft placement for wound closure with the goal to remove local disease burden, improving systemic symptoms, and increasing overall quality of life. The patient proved the importance of operative management through the successful outcome of surgical intervention as her symptoms improved.

Literature in the realm of breast cancer has indicated the benefits of palliative surgical intervention especially pertaining to significant improvement in quality of life. While the survival benefits of operative intervention remain debatable, the palliation allotted by surgery warrants its use in addition to medical and oncological management for patients with end stage diseases.

It is imperative to determine situations where surgery may be used, and to mitigate barriers to providing patients optimal palliative care. Given the benefits attained by this patient through surgery, it is proposed that surgery be considered as an approach to improving quality of life and that surgical management be further employed as a means of palliation.

\section{Funding}

This research received no specific grant from any funding agency in the public, commercial, or not-forprofit sectors.

\section{Conflict of Interest}

The authors have read and approved the final version of the manuscript. The authors have no conflicts of interest to declare.

\section{References}

[1] Amann E, Huang DJ, Weber WP, EppenbergerCastori S, Schmid SM, Hess TH, Güth U. Diseaserelated surgery in patients with distant metastatic breast cancer. Eur J Surg Oncol. 2013 Nov;39(11):1192- 
Citation: Rostami S, Ladd SB, Stewart L, Battista J. Palliative Modified Radical Mastectomy to Improve Quality of Life by Decreasing Disease Burden: A Case Report . Asp Biomed Clin Case Rep. 2021 Jul o2;4(2):119-24.

Case Report

98. [PMID: 24029666]

[2] Kai M, Kubo M, Kawaji H, Kurata K, Mori H, Yamada M, Nakamura M. QOL-enhancing surgery for patients with HER2-positive metastatic breast cancer. BMJ Support Palliat Care. 2019 Jun;9(2):151-54. [PMID: 30254019]

[3] Lotersztajn N, Héquet D, Mosbah R, Rouzier R. Place du traitement chirurgical locorégional chez les patientes présentant un cancer du sein métastatique d'emblée [Locoregional surgery for stage IV breast cancer patients]. Gynecol Obstet Fertil. 2015 Apr;43(4):304-308. French. [PMID: 25819388]

[4] Ogiya A, Takahashi K, Sato M, Kubo Y, Nishikawa N, Kikutani M, Tadokoro Y, Tanaka K, Uematsu T, Watanabe J, Kasami M, Yamasaki S. Metastatic breast carcinoma of the abdominal wall muscle: a case report. Breast Cancer. 2015 Mar;22(2):206-209. [PMID: 22382812]

[5] Ogundiran TO, Ayandipo OO, Ademola AF, Adebamowo CA. Mastectomy for management of breast cancer in Ibadan, Nigeria. BMC Surg. 2013 Dec 19;13:59. [PMID: 24354443]

[6] Padilha M, Gonçalves S, Fardilha C, Melo G, Miranda C, Alves P. Hipofraccionamento no Carcinoma Localmente Avançado da Mama: Esquema "Flash" [Hypofractionation in locally advanced breast cancer: "flash" scheme]. Acta Med Port. 2013 MarApr;26(2):98-101. Portuguese. [PMID: 23809739]

[7] Sio TT, Joliat GR, Jrebi N. Multidisciplinary approach to uncommon, widely metastatic breast cancer. Eur Rev Med Pharmacol Sci. 2014;18(6):84650. [PMID: 24706309]

[8] Shibasaki S, Jotoku H, Watanabe K, Takahashi M. Does primary tumor resection improve outcomes for patients with incurable advanced breast cancer? Breast. 2011 Dec;20(6):543-47. [PMID: 21775141]

[9] Vetter M, Huang DJ, Bosshard G, Güth U. Breast cancer in women 80 years of age and older: a comprehensive analysis of an underreported entity. Acta Oncol. 2013 Jan;52(1):57-65. [PMID: 23083423]

[10] Villalón-López JS, Souto-del Bosque R, AlonsoBriones MV, Trujillo-de Anda AP. Carcinosarcoma mamario una rara entidad con pronóstico fatal. A propósito de un caso [Carcinosarcoma of the breast a rare entity with fatal prognosis. One case report]. Cir Cir. 2013 Jul-Aug;81(4):328-32. Spanish. [PMID: 25063898]
[11] Akiyama Y, Iwaya T, Shioi Y, Endo F, Ishida K, Kashiwaba M, Otsuka K, Nitta H, Koeda K, Mizuno M, Kimura Y, Sasaki A. Successfully treated advanced esophageal cancer with left axillary lymph node metastasis and synchronous right breast cancer: a case report. Surg Case Rep. 2015 Dec;1(1):94. [PMID: 26943418]

[12] Co M, Ng J, Kwong A. De-novo metastatic breast cancers with or without primary tumor resection - A 10-year study. Cancer Treat Res Commun. 2019;19:100118. [PMID: 30825858]

[13] Elshafiey MM, Zeeneldin AA, Elsebai HI, Moneer M, Mohamed DB, Gouda I, Attia AA. Epidemiology and management of breast carcinoma in Egyptian males: experience of a single Cancer Institute. J Egypt Natl Canc Inst. 2011 Sep;23(3):115-22. [PMID: 22776816]

[14] Kuechle JB, McGrath BE, Khoury T, Mindell ER. A case of long term survival with skeletal only metastatic breast cancer. Int J Surg Case Rep. 2015;6C:280-84. [PMID: 25556998]

[15] Kuranishi F, Ohno T. Eradication of breast cancer with bone metastasis by autologous formalin-fixed tumor vaccine (AFTV) combined with palliative radiation therapy and adjuvant chemotherapy: a case report. World J Surg Oncol. 2013 Jun 4;11:127. [PMID: 23734861]

[16] Hussain T, Elahi B, McManus P, Mahapatra T, Kneeshaw PJ. Gastric obstruction secondary to metastatic breast cancer: a case report and literature review. J Med Case Rep. 2012 Aug 7;6:232. [PMID: 22870880]

[17] Medina-Franco H, Suárez-Bobadilla YL. Papel de la cirugía en pacientes con cáncer de mama metastásico [Role of surgery in metastatic breast cancer]. Rev Invest Clin. 2012 Jan-Feb;64(1):81-88. Spanish. [PMID: 22690533]

[18] Moon SH, Jung JH, Lee J, Kim WW, Park HY, Lee $\mathrm{JW}$, Lee SJ. Complete remission of giant malignant phyllodes tumor with lung metastasis: A case report. Medicine (Baltimore). 2019 May;98(22):e15762. [PMID: 31145295]

[19] Nieder C, Mannsåker B, Haukland E. Exceptional Responses to Standard Therapy in a Patient with Metastatic HER2-Positive Breast Cancer. Cureus. 2017 Jun 29;9(6):e1412. [PMID: 28856077]

[20] Pérez-Fidalgo JA, Pimentel P, Caballero A, Bermejo B, Barrera JA, Burgues O, Martinez-Ruiz F, 
Citation: Rostami S, Ladd SB, Stewart L, Battista J. Palliative Modified Radical Mastectomy to Improve Quality of Life by Decreasing Disease Burden: A Case Report . Asp Biomed Clin Case Rep. 2021 Jul 02;4(2):119-24.

\section{Case Report}

Chirivella I, Bosch A, Martínez-Agulló A, Lluch A. Removal of primary tumor improves survival in metastatic breast cancer. Does timing of surgery influence outcomes? Breast. 2011 Dec;20(6):548-54. [PMID: 21816613]

[21] Ruiterkamp J, Ernst MF. The role of surgery in metastatic breast cancer. European Journal of Cancer. 2011 Sep 1;47:S6-22.

[22] Ruiterkamp J, Voogd AC, Bosscha K, Tjan-Heijnen VC, Ernst MF. Impact of breast surgery on survival in patients with distant metastases at initial presentation: a systematic review of the literature. Breast Cancer Res Treat. 2010 Feb;120(1):9-16. [PMID: 20012891]

[23] Scheipl S, Moinfar F, Leithner A, Sadoghi P, Jorgensen M, Rinner B, Liegl B. Tumour-to-tumour metastasis: male breast carcinoma metastasis arising in an extrapleural solitary fibrous tumour - a case report. Diagn Pathol. 2014 Nov 25;9:203. [PMID: 25420931]

[24] Warren LE, Guo H, Regan MM, Nakhlis F, Yeh ED, Jacene HA, Hirshfield-Bartek J, Overmoyer BA, Bellon JR. Inflammatory Breast Cancer: Patterns of Failure and the Case for Aggressive Locoregional Management. Ann Surg Oncol. 2015 Aug;22(8):2483-91. [PMID: 25791789]

[25] Li JJX, Chan WC, Chau HHL, Wu C, Tse GM. Cytologic diagnosis of metastatic malignant phyllodes tumor of the breast in pleural effusion. Diagn Cytopathol. 2019 Jun;47(6):599-602. [PMID: 30829462]

[26] Teshome M. Role of Operative Management in Stage IV Breast Cancer. Surg Clin North Am. 2018 Aug;98(4):859-68. [PMID: 30005779]

[27] Yip CH. Palliation and breast cancer. J Surg Oncol. 2017 Apr;115(5):538-43. [PMID: 28097656] 